\title{
DAMS SAFETY INDEX (DSI): A REASSESSMENT OF THE PARAMETERS OF ANALYSIS
}

\author{
Lucas do C. Garcia1, André L. S. S. Martim², José G. Dalfré Filho², Laura M. C. F. Fais ${ }^{1 *}$ \\ ${ }^{1 *}$ Corresponding author. FT, Unicamp/ Limeira - SP, Brasil. \\ E-mail: laura@ft.unicamp.br | ORCID ID: https://orcid.org/0000-0002-8612-5415
}

\section{KEYWORDS}

Dam Safety Index, small dams, statistical weighting.

\begin{abstract}
Dams provide a water supply, irrigation and power generation. However, the economic, social and environmental impacts are serious when they rupture. It is important that dams continue to function properly and are constantly evaluated for their safety and functionality. Contrary to general belief, small dams are the ones that present the most problems, because they are often built without adequate design and construction methods. One of the methods to evaluate the safety of a dam is through the Dam Safety Index (DSI), which may not entirely avoid subjectivity in dam safety assessment but does propose balanced individual subjectivities in determining the weights of the index criteria. The DSI can also assist managers with preventive maintenance schedules in a dam safety assessment. This work aims to reassess the importance of the parameters of the DSI based on a new weighting of these criteria. The modification of the DSI shows a new bias in the weighting of the criteria that composes the index, not only considering technical aspects, but also legal and environmental ones.
\end{abstract}

\section{INTRODUCTION}

Dams have served humanity since antiquity. Even with the advancement of construction techniques and the availability of cutting-edge monitoring equipment, accidents are still common, both in Brazil and in other countries. However, unlike other countries, where laws for the safety of dams are older, in Brazil, the regulations were only formed in 2010. According to the criteria defined by each regulatory agency, dams are classified by risk category (RC) and associated potential damage.

Despite the efforts of the regulatory agencies, according to the Dam Safety Report prepared by the Brazilian National Water Agency in 2018, only $18 \%$ of the dams registered are subject to the law application and many of them do not have the necessary information to be classified. In addition, there is not necessarily an association between the RC and the level of safety of the dam, since several of them are classified with medium/low RC present significant problems; consequently, it is necessary to improve or supplement the classification criterion. Therefore, much still needs to be done to make the law more effective.

The literature shows that most of the registered dams are considered small, but it is these dams that experience the most accidents (ICOLD (2011); Algorta et al., (2015); Hintze et al. (2016); Jing et al. (2018)). According to
Pisaniello et al., (2015), in developing countries, small dams account for over $90 \%$ of dam failure disasters, which often have catastrophic consequences for the downstream community, infrastructure and environment. Thus, it is necessary to develop a dam safety model that considers the theoretical aspects, the existing laws and that is easily applied by the managers of dams.

In this context, risk analysis tools are considered to evaluate the degree of safety of the structure. However, when considering small dams, the use of indexes is simpler than the usual risk analysis tools to provide general information regarding the structure. For Pimenta et al. (2013), indexes in general do not specifically treat the sequence of events that may lead to failure of a dam, but they can contribute to decision-making in the initial phases of risk management.

Several authors have worked with indexes to evaluate dam safety. Sun et al. (2014) and Zheng et al. (2015) used a multi-criteria decision-making technique to identify and rank the risks of dams. Aguiar et al. (2015) modified the Dam Safety Index (DSI), proposed by Zuffo (2005), by incorporating new relevant criteria. The authors stated that indexes such as this, which consider criteria based on value functions, are important to decrease subjectivity in the dam safety assessment. Lastly, the DSI allows for both the overall 
and punctual views of the safety, helping to prioritise periodic and predictive actions for dam structure maintenance.

Zhou et al. (2015) also worked with dam risk classifications, which are an important part of the risk management. Notwithstanding, dam risk classifications should consider the probability of dam failure and the potential damage. Morales-Torres et al. (2016) reported that risk analysis can provide very suitable and useful information to manage the safety of critical civil infrastructures. Indeed, the results of quantitative risk models can be used to prioritise safety investments for dam safety.

An important point to consider regarding dam safety work is legislation. Aydemir \& Güven (2017) stated that risk prioritisation systems should be used in accordance with dam safety regulations to prevent disasters.

The determination of the criteria (and their respective weights) that compose an index is an important step to assessment dam safety, since the results can be used in a multiple criteria model. According to Zamarrón-Mieza et al. (2017), from a holistic perspective of dam management, a multi-stakeholder and multi-criteria approach is strongly needed to assess not only the risks but also the benefits, costs and opportunities derived from repair, upgrade and removal measures applicable to agingdam management.

According to Jing et al. (2018), the losses caused when a dam breaks are very serious, making it necessary to look for a general assessment method to monitor dam safety and to avoid dam breaking. The authors proposed a fuzzy assessment method for small-sized reservoir risk analysis that quantitatively considers the influence degree and weight of various risk factors.

When considering small earth dams in rural areas with their most diverse uses in agricultural engineering, the use of the DSI can not only provide a general evaluation of the state of the structure, but can also classify the dam into an $\mathrm{RC}$ that is capable of prioritising investments for preventive maintenance, according to this classification.

Thus, this study aims to revaluate the weights of the criteria that compose the DSI proposed by Zuffo (2005) and modified by Aguiar (2015), verifying changes in the bias of the importance of the criteria.

\section{MATERIAL AND METHODS}

The DSI is a general classification index to estimate the safety value and qualify dam risk failure; its application allows us to evaluate several individual characteristics of a structure. The proposal of a DSI is to reduce subjectivity in safety assessments through the contribution of technicians and a statistical treatment for a series of weights assigned to each criterion among a list of various options. In order to guarantee the most comprehensive contribution of the technicians, this research was carried out with a number of specialists in dams, in which each one contributed by answering a questionnaire that includes the analysis of 22 safety criteria.

The DSI is calculated according to Aguiar et al. (2015), which modified the index prior proposed by Zuffo (2005) and is the product of criteria grades (product of sequences) related to the safety issues of a dam, ensuring that all criteria will be verified. The use of the product also ensures that all the criteria have significance in the final grade. The DSI is expressed by [eq. (1)]:

$$
D S I=\prod_{i=1}^{n} q_{i}^{w i}
$$

Where:

$\mathrm{i}$ is a dummy variable of a criterion sequence, since 1 until $n$;

$\mathrm{n}$ is the number of criteria that compose the DSI;

$\mathrm{q}_{\mathrm{i}}$ is a grade of the $\mathrm{i}^{\text {th }}$ criterion, a number between 1 and 100 , obtained from the respective function of value according to the concept in each criterion,

$\mathrm{W}_{\mathrm{i}}$ is the weight to the $\mathrm{i}^{\text {th }}$ criterion, which is a value between 0 and 1 , corresponding to its percentage importance to global safety.

The standardised weights $\left(\mathrm{w}_{\mathrm{i}}\right)$ were established from the technical assessment of the specialists:

$$
\sum_{i=1}^{n} w_{i}=1
$$

To determine the relevance of each criterion in the general dam safety assessment and to revaluate the weights of each of them, research with specialists was performed through a questionnaire sent to professionals from Brazil and other countries, via email, and through existing dam safety groups in platforms, such as LinkedIn ${ }^{\circledR}$ and Yahoo Groups ${ }^{\circledR}$. The questionnaire was available for responses for one month, through the link https://goo.gl/forms/8aMnOu wvNaq6nIqr1. The professionals consulted included mainly civil engineers and others with some involvement in the design, installation, operation, maintenance and dam safety, both in the technical and academic areas.

All the 22 criteria that compose the DSI were analysed again by specialists, but this time in a qualitative way through the scale of importance: not important; low importance; important; very important; extremely important. After this qualitative scale was converted into quantitative, so as the weight of each criterion is calculated. A range of decreasing values was assigned for the categories of responses, with being " 5 " extremely important and " 1 " being not important.

With the result of the questionnaires, the weight of each criterion was calculated from a statistical treatment of the grades contained in the questionnaires. For each criterion, the mean (M) was calculated by [eq. (3)] and the standard deviation by [eq. (4)]:

$$
\begin{aligned}
& M=\frac{\sum_{i=1}^{m} a_{i}}{m} \\
& D P=\sqrt{\sum_{i=1}^{m} \frac{\left(a_{i}-M\right)^{2}}{m-1}}
\end{aligned}
$$

Where:

$\mathrm{m}$ is the number of notes assigned to each criterion;

$a_{i}$ is the $i^{\text {th }}$ note of the same criterion assigned by the specialists.

Therefore, the weight related to each one of the criterion was calculated through [eq. (5)], so that the sum of the weights was adopted to be 1.0 : 


$$
P_{i}=\frac{\overline{\mathrm{X}_{1}}}{\sum_{1}^{\mathrm{i}} \overline{\mathrm{X}_{1}}}
$$

Where:

$P_{i}$ is the weight of the $i^{\text {th }}$ criterion,

$\bar{X}_{l}$ is the mean of the $\mathrm{i}^{\text {th }}$ criterion.

\section{RESULTS AND DISCUSSION}

The questionnaire was sent by email to 152 professionals, with only 21 responding. Considering this, the questionnaires were also sent directly to dam safety professional groups, with the return of 70 questionnaires, with 38 Brazilian professionals and 32 international. In total, a significant number of participants answered the questionnaire, which allowed a refinement of the DSI and a new evaluation of the weights of each criterion. Figure 1 shows the distribution of the answers obtained for each criterion of the DSI, where the values of the left side of the bars represent the answers concerning the importance levels of "extremely important" and "very important".

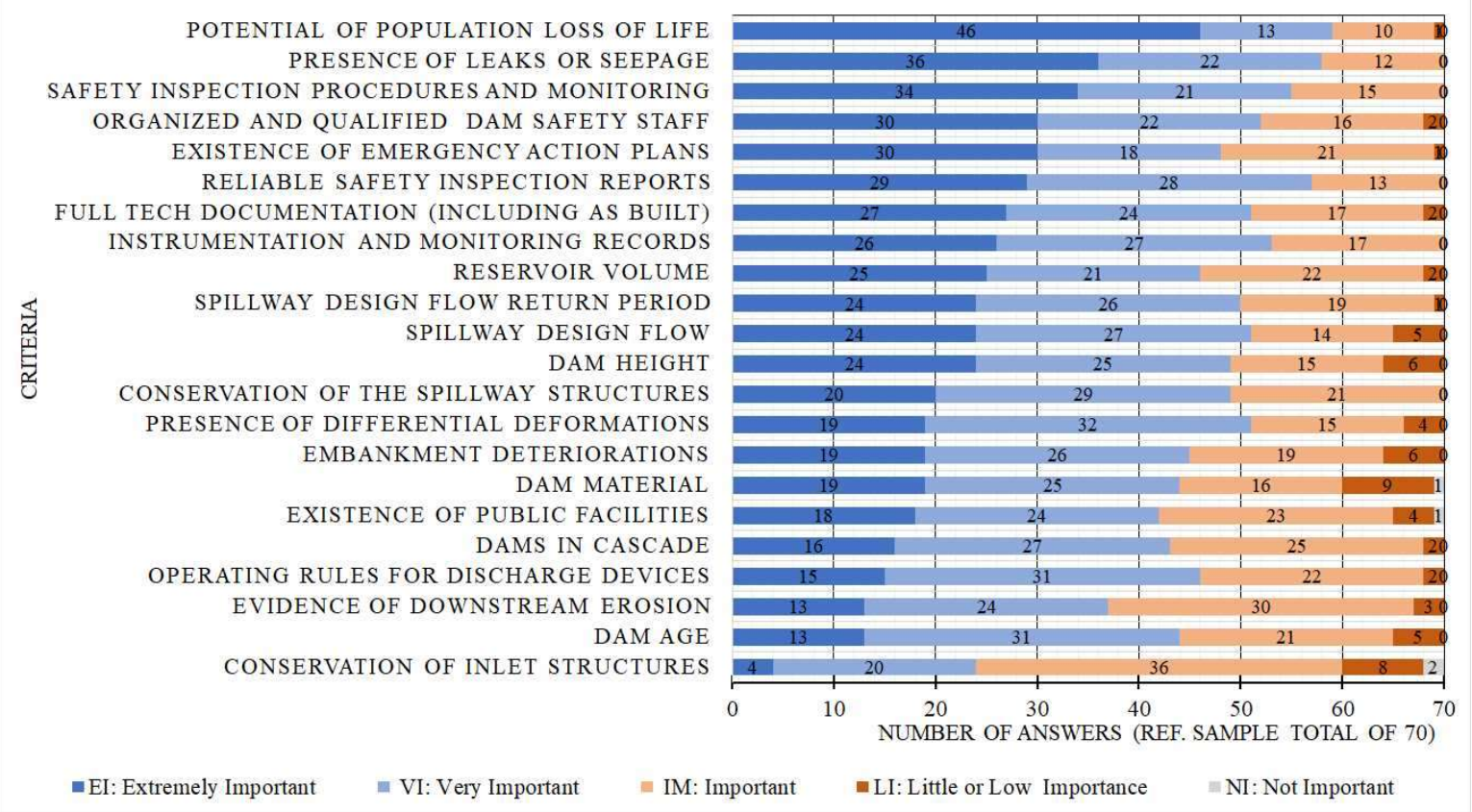

FIGURE 1. Distribution of answers by importance of criteria.

It should be considered that the professionals tend to answer the questions according to their academic education, training and area of activity. Most of the technicians consulted in this work are civil engineers specialising in geotechnics, water resources or the safety of dams. However, their areas of activity are quite varied, including professors, researchers, hydraulic work sector, energy, water resources, concrete technology, safety of dams and so on.

The evaluation of the importance of each criterion is a subjective characteristic, since this analysis depends on the technician expertise. Therefore, the evaluation of criteria through a statistical weighting reduces the subjectivity of the analysis.

One may note that the answers "extremely important" and "very important" represent more than 50\% of all the 22 criteria that compose the DSI, which evidences that the chosen ones by Aguiar et al. (2015) really represent relevant technical criteria regarding the safety of dams. That is, the large number of responses with values indicated as "extremely important" and "very important" shows that all these aspects are relevant to evaluate the safety of dams, resulting in relatively close weights.

From the assignment of the values to the qualitative responses, the average, standard deviation and weight of each parameter evaluated were determined (through Equations (3)-(5)) and the results are shown in Figure 2.

Generally, the most important criterion was the "potential population loss of life" while "conservation of inlet structures" was pointed out as the least relevant for the DSI calculation. Among the analysed criteria, the one with the highest standard deviation and therefore the lowest consensus among professionals was "dam material". The lowest standard deviation was referred to the parameter "reliable safety inspection reports". 


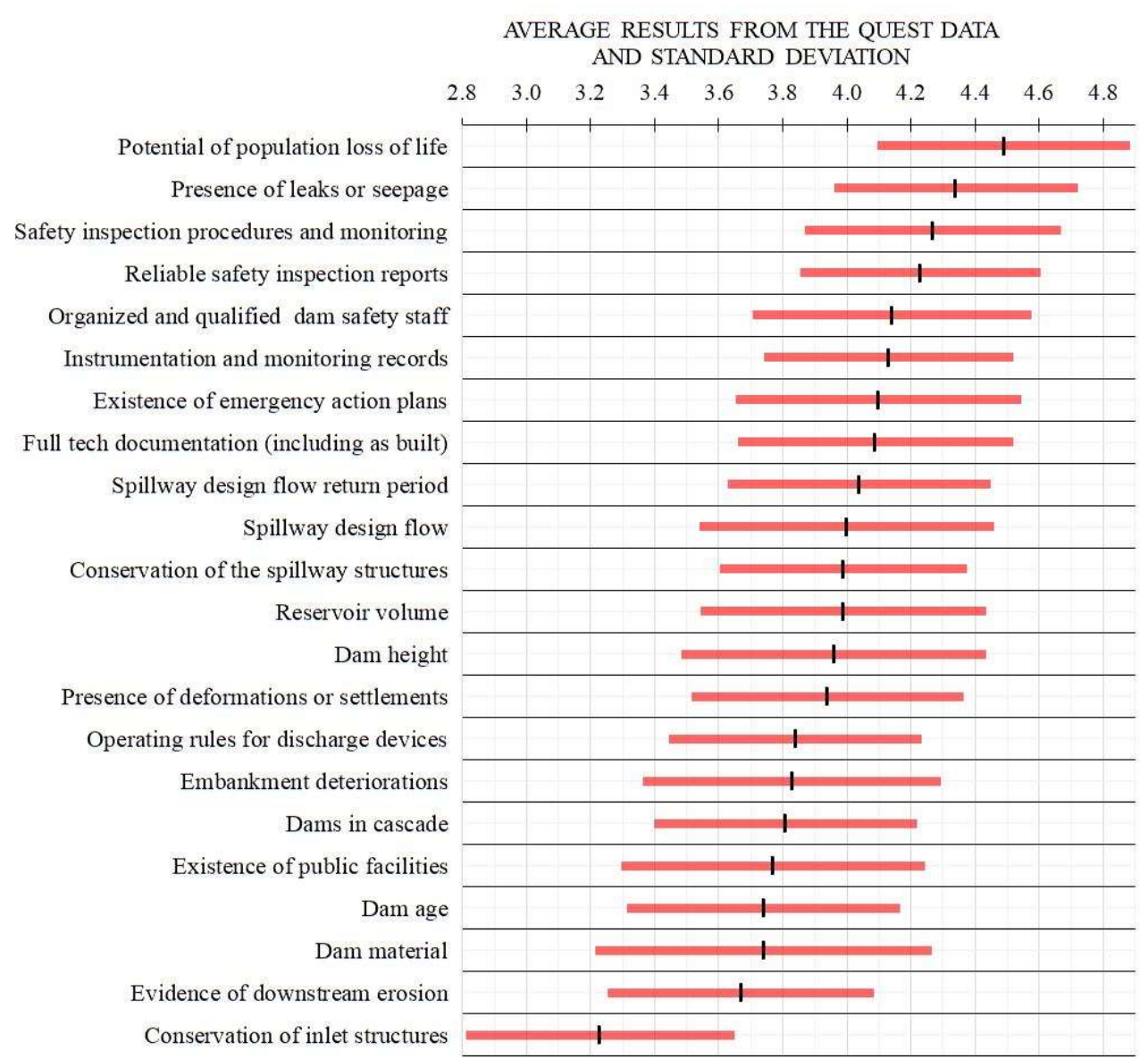

FIGURE 2. Average results from questionnaire and standard deviation of each criterion.

Figure 3 shows that all criteria had a greater difference in weights, according to the evaluation of the technicians, when compared to those obtained by Aguiar et al. (2015).

One may note that there was a significant change in relation to the technical evaluation of the consulted professionals, who are now more concerned with legal issues related to documentation and indirect characteristics of the dam (such as the existence of design documentation) and less concerned about characteristics directly related to the structure of the dam (such as type of material and presence of deformations). This change may be related to recent accidents that occurred, with serious consequences, such as the disruptions of Fundão Dam in Mariana-MG, Córrego do Feijão Dam in Brumadinho-MG and a small earth dam on the Peixe river in Pedro Alexandre-BA. 


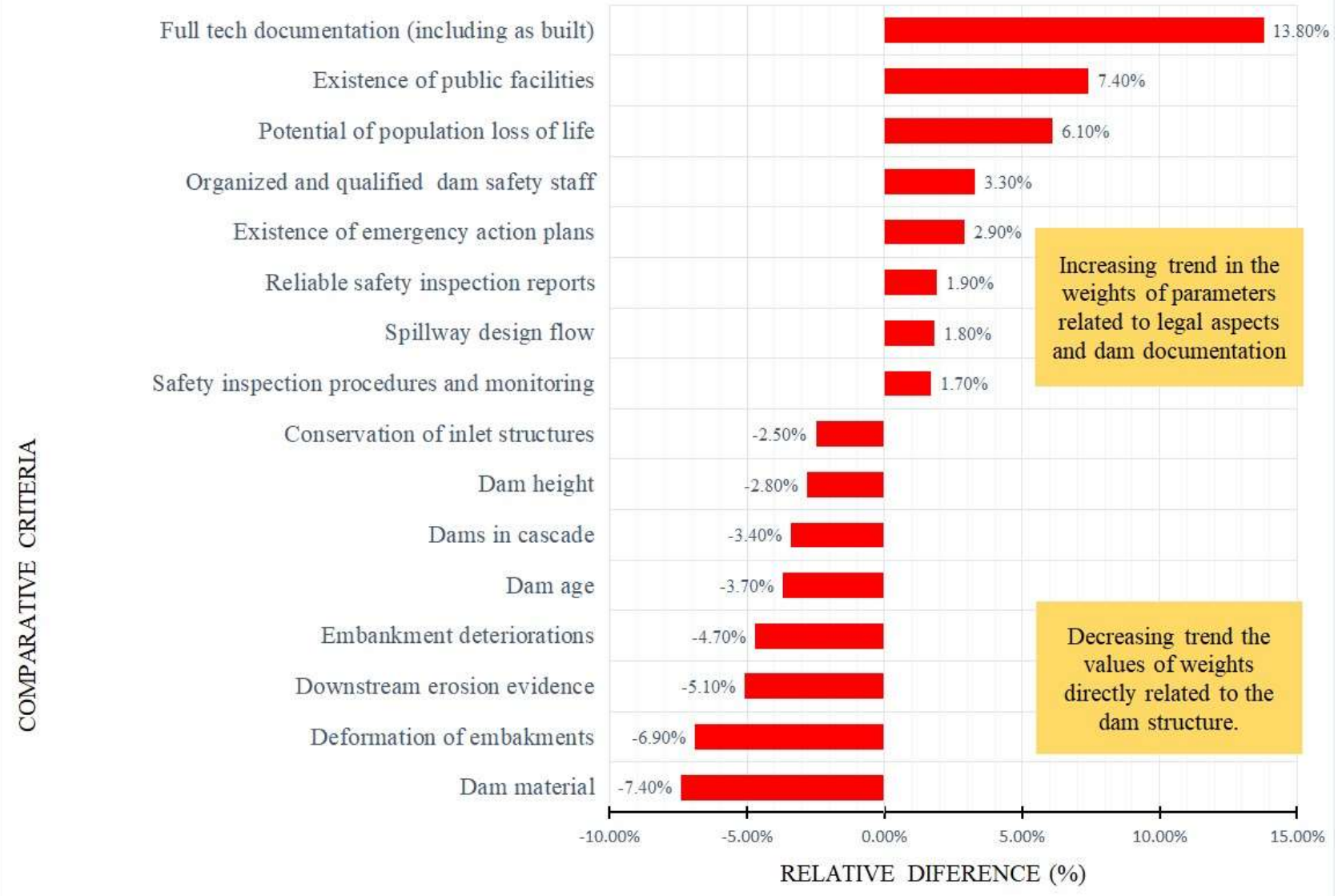

FIGURE 3. Primary relative difference between the weights obtained in this work (2017) and in Aguiar et al. (2015).

The modification of the DSI showed a new bias in the weighting of all criteria that compose the index, not only considering technical aspects, but also legal and environmental ones. Thus, after the disruptions in Mariana Dam in 2015 and Brumadinho Dam in 2019, the results point to a greater emphasis on criteria related to legislative aspects compared to technical aspects. In addition, some of the resolutions that complement the National Dam Safety Policy were approved after these recent events, demanding for a special attention to the Emergency Action Plans and their applicability, as well as the integration of actions with civil defences.

\section{CONCLUSIONS}

Brazil has long-established methods and design criteria for the construction of earth dams. However, these have not been sufficient for preventing accidents, which shows that there are other factors to be considered in dam safety assessment. The literature review showed several works on the safety of dams based on risk analysis with complex mathematical models. When considering small dams, it is useful instead to prioritise criteria to be considered in the analysis using indexes.

The Dam Safety Index (DSI) presented in this work is a method to evaluate the safety of dams through weighted criteria according to their level of importance. In addition to the classification of the category of risk category of a dam, the DSI has also the purpose of ranking a list of dams, relating the most vulnerable and those that may require a detailed risk analysis, which is more time and cost consuming. The DSI is a method that may not completely avoid subjectivity in dam safety assessment, but it proposes to balance individual subjectivities in determining the weights of the index criteria.

It is possible to verify that the changes made in the legislation occurred after the recent disruptions in Minas Gerais, Brazil. The main changes were regarding the potentially affected populations and they do not propose changes in the matrices of the dam risk category and potential associated damage.

Furthermore, for small dams, the DSI method with weights of well-defined criteria can indicate which elements of the structure should receive immediate intervention, dispensing analyses that require more resources and that may prove impracticable, especially for small dams in rural areas that do not have their own technical staff.

In a next step of this work, the value functions of the DSI criteria will be defined so that it can be applied in the dams of the city of Campinas - SP.

\section{ACKNOWLEDGMENTS}

The authors are grateful for financial assistance from the National Council of Scientific and Technological Development (CNPq).

\section{REFERENCES}

Aguiar DP de O, Fais LMCF, Dalfré Filho JG, Genovez AIB (2015) Contribuição ao estudo do Índice de Segurança de Barragens - ISB. Revista Brasileira de Recursos Hídricos 20(2):360-368. 
Algorta J, Pairet RL, Bustamente M (2015) La ingeniería de las presas de riego en el Uruguay. In: Congreso Argentino de Presas y Aprovechamientos Hidroeléctricos. Santa Fe, Argentina.

Aydemir A, Güven A (2017) Modified risk assessment tool for embankment dams: case study of three dams in Turkey. Civil Engineering and Environmental Systems 34(1):53-67. DOI:

http://dx.doi.org/10.1080/10286608.2017.1300794

Brazilian National Water Agency (2018) Dams Safety Report. Brasilia, Brasil.

Hintze F, Duro V, Carvalho JC.; Eira C, Rodrigues PC, Vingada J (2016) Influence of Reservoirs Created by Small Dams on the Activity of Bats. Acta Chiropterologica 18(2):395-408. DOI:

http://dx.doi.org/10.3161/15081109ACC2016.18.2.007

ICOLD - International Commission on Large Dams (2011) Small dams: design, surveillance and rehabilitation. Paris, The International Committee on Large Dams.

Jing M, Yang J, Li S, Wang L (2018) Application of fuzzy analytic hierarchy process in the risk assessment of dangerous small-sized reservoirs. International Journal of Machine Learning \& Cybernetics 9:113-123. DOI: https://doi.org/10.1007/s13042-015-0363-4

Morales-Torres A, Serrano-Lombillo A, Escuder-Bueno I, Altarejos-Garcia L (2016) The suitability of risk reduction indicators to inform dam safety management. Structure and Infrastructure Engineering 12(11):1465-1476. DOI: https://doi.org/10.1080/15732479.2015.1136830
Pimenta L, Caldeira L, Das Neves EM (2013) A new qualitative method for the condition assessment of earth and rockfill dams. Structure and Infrastructure Engineering 9(11):1103-1117.

Pisaniello JD, Dam TT, Tinker-Holyoak JL (2015) International small dam safety assurance policy benchmarks to avoid dam failure flood disasters in developing countries. Journal of Hydrology 531:1141-1153.

Sun R, Zhou Z, Ao X, Sun X, Songet M (2014) Study of the comprehensive risk analysis of dam-break flooding based on the numerical simulation of flood routing. Part I: model development. Natural Hazards 73(3):1547-1568. DOI: https://doi.org/10.1007/s11069-014-1154-Z

Zamarrón-Mieza I, Yepes V, Moreno-Jimenez JM (2017) A systematic review of application of multi-criteria decision analysis for aging-dam management. Journal of Cleaner Production 147:217-2320. DOI: https://doi.org/10.1016/j.jclepro.2017.01.092

Zheng X, Gu C, Qin D (2015) Dam's risk identification under interval-valued intuitionistic fuzzy environment. Civil Engineering and Environmental Systems 32(4):351-363. DOI: http://dx.doi.org/10.1080/10286608.2015.1046052

Zhou X, Zhou J, Du X, Li S (2015) Study on dam risk classification in China. Water Science \& Technology: Water Supply 15(3):483-489.

Zuffo MSR (2005) Metodologia para Avaliação da Segurança de Barragens. Dissertação Mestrado, Campinas, Universidade de Campinas, Faculdade de Engenharia Civil, Arquitetura e Urbanismo. 